\title{
PROPERTIES OF COMPLEX SYMMETRIC OPERATORS
}

\author{
Sungeun Jung, Eungil Ko And Ji Eun LeE
}

\begin{abstract}
An operator $T \in \mathscr{L}(\mathscr{H})$ is said to be complex symmetric if there exists a conjugation $C$ on $\mathscr{H}$ such that $T=C T^{*} C$. In this paper, we prove that every complex symmetric operator is biquasitriangular. Also, we show that if a complex symmetric operator $T$ is weakly hypercyclic, then both $T$ and $T^{*}$ have the single-valued extension property and that if $T$ is a complex symmetric operator which has the property $(\delta)$, then Weyl's theorem holds for $f(T)$ and $f(T)^{*}$ where $f$ is any analytic function in a neighborhood of $\sigma(T)$. Finally, we establish equivalence relations among Weyl type theorems for complex symmetric operators.
\end{abstract}

Mathematics subject classification (2010): Primary 47A11, 47A53. theorem.

Keywords and phrases: complex symmetric operator, biquasitriangular, weakly hypercyclic, Weyl type

\section{REFERENCES}

[1] P. AiEnA, Fredholm and local spectral theory with applications to multipliers, Kluwer Academic Pub. 2004.

[2] P. Aiena, M. L. Colas Ante, And M. GonZA'LeZ, Operators which have a closed quasi-nilpotent part, Proc. Amer. Math. Soc. 2002.

[3] M. Amouch And H. ZGUitTi, On the equivalence of Browder's and generalized Browder's theorem, Glasgow Math. J. 48 (2006), 179-185.

[4] C. Apostol, C. FoiAs, AND D. VoiculesCu, Some results on non-quasitriangular operators, Rev. Roum. Math. Pures et Appl. 20 (1975), 159-181.

[5] C. Apostol, H. Bercovici, C. Foias, And C. Pearcy, Quasiaffine transforms of operators, Michigan Math. J. 29 (1982), 243-255.

[6] M. BERKANI, On a class of quasi-Fredholm operators, Int. Eq. Op. Th. 34 (1999), 244-249.

[7] M. Berkani And J. J. Koliha, Weyl type theorems for bounded linear operators, Acta Sci. Math. 69 (2003), 359-376.

[8] I. COLOJOARA AND C. FoIAs, Theory of generalized spectral operators, Gordon and Breach, New York, 1968.

[9] R. E. CURTo AND Y. M. HAN, Weyl's theorem, a-Weyl's theorem, and local spectral theory, J. London Math. Soc. 2 (2003), 499-509.

[10] R. G. Douglas And C. Pearcy, A note on quasitriangular operators, Duke. Math. J. 37 (1970), $177-188$.

[11] L. A. Fialkow, The similarity orbit of a normal operator, Trans. Amer. Math. Soc. 210 (1975), 129-137.

[12] T. FURUTA, Invitation to linear operators, London and New York, 2001.

[13] S. R. GARCIA, Conjugation and Clark Operators, Contemp. Math. 393 (2006), 67-112.

[14] S. R. GARCiA, Means of unitaries, conjugations, and the Friedrichs operator, J. Math. Anal. Appl. 335 (2007), 941-947.

[15] S. R. Garcia And M. Putinar, Complex symmetric operators and applications, Trans. Amer. Math. Soc. 358 (2006), 1285-1315.

[16] S. R. Garcia And M. Putinar, Complex symmetric operators and applications II, Trans. Amer. Math. Soc. 359 (2007), 3913-3931.

[17] S. R. GARCIA AND W. R. Wogen, Complex symmetric partial isometries, J. Funct. Anal. 257 (2009), $1251-1260$. 
[18] S. R. GARCiA AND W. R. Wogen, Some new classes of complex symmetric operators, Trans. Amer. Math. Soc. 362 (2010), 6065-6077.

[19] P. R. Halmos, A Hilbert space problem book, seconded., Springer-Verlag, New York, 1982.

[20] R. E. Harte AND W. Y. LeE, Another note on Weyl's theorem, Trans. Amer. Math. Soc. 349 (1997), 2115-2124.

[21] S. V. DJoRdjeVIĆ AND Y. M. HAN, Browder's theorems and spectral continuity, Glasgow Math. J. 42 (2000), 479-486.

[22] R. HARTE, Invertibility and singularity for bounded linear operators, Marcel Dekker Inc., New York and Basel, 1988.

[23] D. Herrero, Approximation of Hilbert space operators, Volume 1, 2nd edn, Pitman Research Notes in Mathematics Series, 1989.

[24] S. JUNG, E. Ko, M. LEE, AND J. LEE, On local spectral properties of complex symmetric operators, J. Math. Anal. Appl. 379 (2011), 325-333.

[25] S. Jung, E. Ko, AND J. LEE, On scalar extensions and spectral decompositions of complex symmetric operators, J. Math. Anal. Appl. 382 (2011), 252-260.

[26] I. JUnG, E. Ko, AND C. PEARCY, Every operator almost commutes with a compact operator, Kyoungpook Math. J. 47 (2007), 221-226.

[27] H. W. Kim AND C. PEARCY, Extensions of normal operators and hyperinvariant subspaces, J. Operator Theory 3 (1987), 203-211.

[28] K. Laursen and M. Neumann, An introduction to local spectral theory, Clarendon Press, Oxford, 2000.

[29] R. Lange And S. WAng, New approaches in spectral decomposition, Contemp. Math. 128, Amer. Math. Soc. 1992.

[30] M. LahrouZ And M. Zohry, Weyl type theorems and the approximate point spectrum, Irish. Math. Soc. Bulletin 55 (2005), 41-51.

[31] B. S. NAGY AND C. Foias, Harmonic analysis of operators on Hilbert space, Akadémiai Kiadó, Budapest, 1970.

[32] G. T. Prajitura, Limits of weakly hypercyclic and supercyclic operators, Glasgow Math. J. 47 (2005), 255-260.

[33] C. PEARCY, Some recent developments in operator theory, C.B.M.S. Regional Conference Series in Mathematics No. 36, Amer. Math. Soc. Providence, 1978. 